\title{
Cutaneous sarcoidosis in a patient with severe asthma treated with omalizumab
}

\author{
Samuel Yung $\mathrm{MD}^{1}$, Duhyun Han², Jason K Lee $\mathrm{MD}^{3}$
}

\begin{abstract}
S Yung, D Han, JK Lee. Cutaneous sarcoidosis in a patient with severe asthma treated with omalizumab. Can Respir J 2015;22(6):315-316.

Omalizumab, a monoclonal anti-immunoglobulin E antibody, has been used as an effective treatment for severe asthma associated with atopy over the past decade. Sarcoidosis is an idiopathic granulomatous disorder in which first-line treatment is usually glucocorticoids. To the authors' knowledge, the present report describes the first case of an association between omalizumab therapy and revelation of cutaneous sarcoidosis with the withdrawal of systemic glucocorticoids. A 56-year-old woman with severe allergic asthma dependent on oral prednisone initiated omalizumab treatment. As her symptoms of asthma improved over the course of a year, her prednisone was gradually tapered. After being off glucocorticoids, she developed skin nodules that had biopsy characteristics of sarcoidosis. The present case illustrates the need to monitor closely for potential unmasking of glucocorticoid-responsive conditions when transitioning from systemic glucocorticoids to omalizumab therapy.
\end{abstract}

Key Words: Asthma; Glucocorticoids; Noncaseating granuloma; Omalizumab

Learning objectives

- To demonstrate the first case of sarcoidosis unmasked by omalizumab treatment and subsequent tapering of systemic glucocorticoids.

- To recognize a rare but possible consequence of glucocorticoid withdrawal

Can MEDS Competency: Collaborator

Pretest

- Describe two disease states that may be unmasked by the withdrawal of systemic glucocorticoids.

$\mathrm{O}^{2}$ malizumab, a monoclonal anti-immunoglobulin E ( $\mathrm{g} \mathrm{E})$ antibody, is indicated for the treatment of severe allergic asthma. Sarcoidosis is an idiopathic granulomatous disorder in which first-line treatment is usually glucocorticoids (1). The present report is the first to describe an association between omalizumab treatment and cutaneous sarcoidosis.

\section{CASE PRESENTATION}

A 56-year-old woman was evaluated in February 2012 for uncontrolled asthma. Her medical history included atopic dermatitis, chronic urticaria, gastroesophageal reflux disease, allergic rhinoconjunctivitis, adrenal insufficiency and osteoporosis. Over the past year, she presented to the emergency department three times for asthma. She required six courses of oral prednisone and $>10$ short-acting beta agonist rescue (salbutamol $100 \mu \mathrm{g}$ per dose) by inhalation every week. She also awoke nightly due to nocturnal symptoms. Between 1997 and 2012, the patient had received fluticasone/salmeterol, montelukast, beclomethasone dipropionate, tiotropium bromide and salbutamol, and chronic prednisone to manage her asthma for at least 10 years. Her prednisone dosage varied from $5 \mathrm{mg}$ to $40 \mathrm{mg}$ daily depending on the

\author{
La sarcoïdose cutanée chez un patient atteint \\ d'asthme sévère traité à l'omalizumab
}

L'omalizumab, un anticorps monoclonal anti-immunoglobuline E, est un traitement efficace de l'asthme sévère associé à l'atopie qui est utilisé depuis dix ans. La sarcoïdose est un trouble granulomateux idiopathique généralement traité par des glucocorticoïdes en première ligne. En autant que le sachent les auteurs, le présent rapport décrit le premier cas d'association entre un traitement à l'omalizumab et la révélation d'une sarcoïdose cutanée après le retrait des glucocorticoïdes systémiques. Une femme de 56 ans ayant un asthme allergique sévère contrôlé par de la prednisone par voie orale a amorcé un traitement à l'omalizumab. Puisque ses symptômes d'asthme se sont atténués sur une période d'un an, sa dose de prednisone a été graduellement réduite. Lorsqu'elle a cessé de prendre des glucocorticoïdes, elle a développé des nodules cutanés qui avaient des caractéristiques de sarcoïdose à la biopsie. Le présent cas démontre la nécessité de rester à l'affût des affections qui réagissent aux glucocorticoïdes au mement de remplacer les glucocorticoïdes systémiques par un traitement à l'omalizumab.

severity of her asthma symptoms. She had been previously treated with immunotherapy for grass and ragweed allergies for 10 years without significant improvement by another allergist. She quit smoking in 2007, with a 15 pack-year history.

Skin allergy testing at assessment revealed allergies to ryegrass, ragweed, weed mix, dogs, cats and dust mites. She was advised to remove all allergic and environmental triggers to the greatest extent possible; however, although she was fully adherent to this instruction, her symptoms remained uncontrolled. Laboratory testing revealed an IgE level of $252 \mathrm{ng} / \mathrm{mL}$ (normal range $0 \mathrm{ng} / \mathrm{mL}$ to $240 \mathrm{ng} / \mathrm{mL}$ ). Pulmonary function testing on March 27, 2012, revealed a forced expiratory volume in $1 \mathrm{~s}$ $\left(\mathrm{FEV}_{1}\right) /$ forced vital capacity $(\mathrm{FVC})$ ratio of 0.65 and an $\mathrm{FEV}_{1}$ of $1.66 \mathrm{~L}$ (71\% predicted value).

Omalizumab was initiated on May 2, 2012, and was ongoing as of May 2015. She remained on fluticasone/salmeterol $250 \mu \mathrm{g} / 50 \mu \mathrm{g}$ two puffs twice daily, beclomethasone dipropionate $200 \mu \mathrm{g}$ two puffs twice daily, tiotropium bromide $18 \mu \mathrm{g}$, and prednisone $5 \mathrm{mg} \mathrm{PO}$ daily with salbutamol as needed. She stopped montelukast in 2011 due to lack of any additive efficacy. Within three months of omalizumab therapy, the asthma was controlled. She experienced no asthma exacerbations, no need for increases in prednisone, no nocturnal symptoms and salbutamol use decreased to once every three weeks. Repeat pulmonary function testing on March 4, 2013, revealed a significantly improved $\mathrm{FEV}_{1} /$ FVC ratio (0.69) and an $\mathrm{FEV}_{1}$ of $1.81 \mathrm{~L}$ (87\% predicted value).

Due to improved asthma control in March 2013, the patient began to consult with an endocrinologist to taper off her prednisone. She was entirely off prednisone in April 2013. On August 26, 2013, the patient noted development of multiple $2 \mathrm{~cm} \times 3 \mathrm{~cm}$ nontender, mobile, nodules on her thighs, which spread to her arms and over her rib cage. She also developed an erythematous rash from the mid tibia bilaterally down to her feet (Figure 1). Biopsies obtained from the nodules showed a granulomatous dermal infiltrate consistent with sarcoidosis. Allergy, St Michael's Hospital, University of Toronto, Toronto, Ontario

Correspondence: Dr Jason K Lee, 123 Edward Street Suite 920, Toronto, Ontario M5G 1E2. Telephone 647-352-2554, fax 866-881-7790, e-mail jason.k.lee.md@gmail.com 


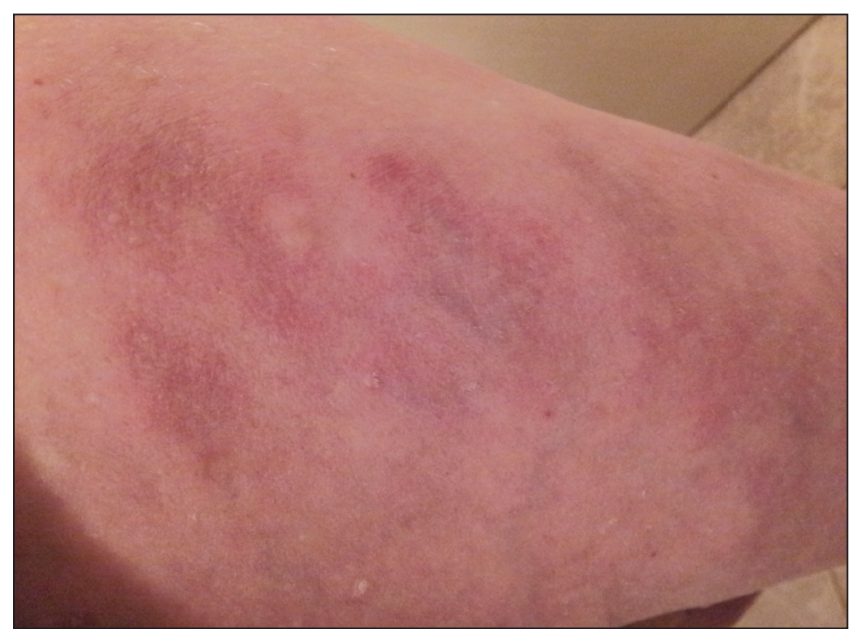

Figure 1) Photograph of the skin rash. $2 \mathrm{~cm} \times 3 \mathrm{~cm}$ nodules and rash appeared on the patient's legs

The biopsies were negative for acid-fast bacilli and fungi, and interpreted by a dermatopathologist experienced with cutaneous sarcoidosis. She subsequently started to take prednisone again to treat her nodules at the recommendation of a cutaneous sarcoidosis expert. A computed tomography scan of her chest performed in December 2013 was negative for parenchymal infiltrates or hilar adenopathy, ruling out pulmonary involvement. No other sites were involved.

\section{Allergic asthma and omalizumab}

\section{DISCUSSION}

Allergic asthma is mediated primarily by IgE. In susceptible individuals, $\mathrm{T}$ cells release cytokines that stimulate the development of $\mathrm{B}$ cells responsible for producing IgE. IgE binds to mast cells, eosinophils and basophils. When there is re-exposure to an allergen, the $\operatorname{IgE}$ stimulates degranulation and release of inflammatory mediators, resulting in asthma (2).

Omalizumab is a humanized murine IgE monoclonal antibody indicated for treatment of allergic asthma, and has been shown to be effective (3-5). Based on her significant improvement in $\mathrm{FEV}_{1}$ and measures of clinical control criteria, this patient clearly improved, allowing a tapering off of her glucocorticoids. It has been reported that $78.8 \%$ of severe asthma patients were able to reduce or stop the use of oral corticosteroids following omalizumab therapy (6).

\section{Sarcoidosis and omalizumab}

The most logical explanation for sarcoidosis appearing after omalizumab treatment is that the prednisone treatment used to control our patient's asthma was also treating the underlying sarcoidosis. When prednisone was tapered, sarcoidosis was unmasked. Interestingly, there have been reports of eosinophilic granulomatosis with polyangiitis (EGPA or Churg-Strauss) in patients on omalizumab therapy for severe asthma. EGPA either preceded omalizumab treatment or was noted shortly after tapering of systemic glucocorticoids. Similar to our case, one of the explanations was that omalizumab therapy allowed unmasking of EGPA with tapering of systemic glucocorticoids $(7,8)$. Another possible explanation is that omalizumab played a causative role in the development of sarcoidosis. Omalizumab blocks IgE binding to its receptors, diminishing dendritic IgE high-affinity receptor expression. This may decrease allergen presentation to $T$ cells, and subsequent production of T-helper (Th) 2 cytokines (9). The authors of this report speculate there may have been a shifting of the Th2 to a Th1 cytokine profile, which is associated with sarcoidosis, especially in the early years of the disease (10). A final possibility is that the development of sarcoidosis shortly after stopping omalizumab was a temporal coincidence, although the authors believe the alternative explanations provided are compelling.

Aside from severe asthma, glucocorticoids are used to treat several other inflammatory conditions. Our case demonstrates a novel association between cutaneous sarcoidosis and withdrawal of systemic glucocorticoids. It would appear prudent for clinicians to be vigilant of corticosteroid-responsive conditions that may be revealed with omalizumab treatment, especially with tapering of systemic glucocorticoids.

\section{Post-test}

- Describe two disease states that may be unmasked by the withdrawal of systemic glucocorticoids.

Sarcoidosis and EGPA.

AUTHOR CONTRIBUTIONS: JKL identified and managed the case, SY and DH performed literature and clinical chart review and drafted the manuscript. JKL reviewed the manuscript and provided critical revision for important intellectual content. All authors read and approved the final manuscript.

DISCLOSURES: DH and SY have no conflict of interest to declare. JKL provides consultancy to ALK, Paladin, Novartis, GSK, Astrazeneca, Sanofi, Alcon, Merck, Takeda, CSL, Omega, and Hollister Stier; speaker honorarium from Novartis, Merck, Takeda, Astrazeneca, CSL and Sanofi,

\section{REFERENCES}

1. Iannuzzi MC, Fontana JR. Sarcoidosis: Clinical presentation, immunopathogenesis, and therapeutics. JAMA 2011;305:391-9.

2. Strunk RC, Bloomberg GR. Omalizumab for asthma. N Engl J Med 2006;354:2689-95

3. Busse W, Corren J, Lanier BQ, et al. Omalizumab, anti-IgE recombinant humanized monoclonal antibody, for the treatment of severe allergic asthma. J Allergy Clin Immunol 2001;108:184-90.

4. Soler M, Matz J, Townley R, et al. The anti-IgE antibody omalizumab reduces exacerbations and steroid requirement in allergic asthmatics. Eur Respir J 2001;18: 254-61. (Erratum Eur Respir J 2001;18:739-40.

5. Busse WW, Morgan WJ, Gergen PJ, et al. Randomized trial of omalizumab (anti-IgE) for asthma in inner-city children. N Engl J Med 2011;364:1005-15.

6. Niven R. A UK Survey of oral corticosteroid use in patients treated with omalizumab. Thorax 2007;62(Suppl 3):A98,P91.

7. Ruppert AM, Averous G, Stanciu D, et al Development of ChurgStrauss syndrome with controlled asthma during omalizumab treatment. J Allergy Clin Immunol 2008;121:253.

8. Wechsler ME, Wong DA, Miller MK, Lawrence-Miyasaki L. Churg-strauss syndrome in patients treated with omalizumab. Chest 2009;136:507.

9. Holgate S, Smith N, Massanari M, Jimenez P. Effects of omalizumab on markers of inflammation in patients with allergic asthma. Allergy 2009;64:1728-36.

10. Grutters JC, van den Bosch JM. Corticosteroid treatment in sarcoidosis. Eur Respir J 2006;28:627. 


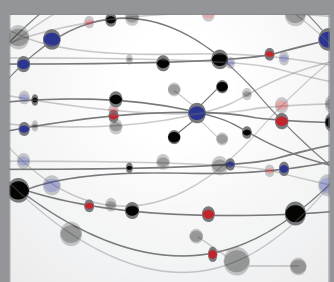

The Scientific World Journal
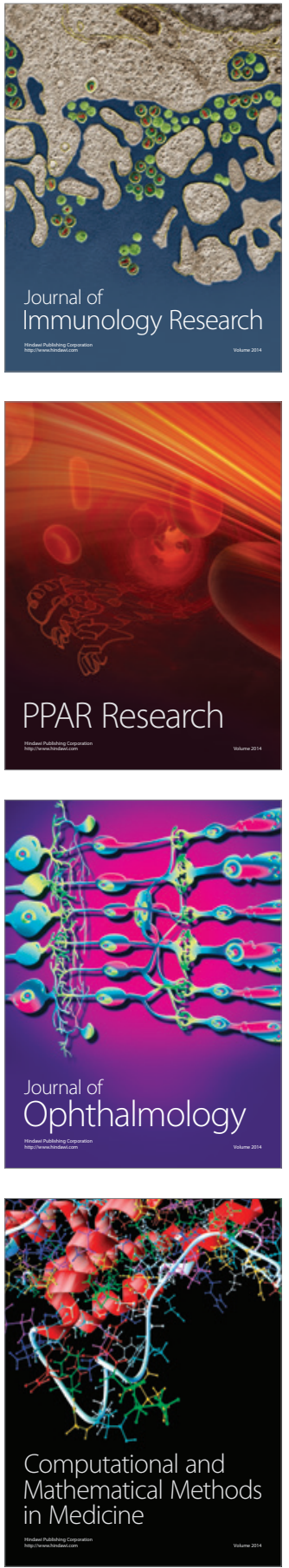

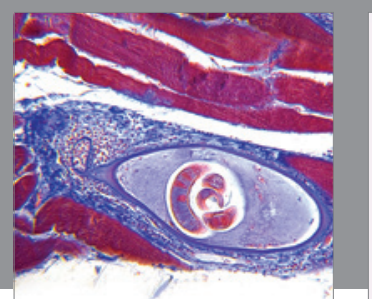

Gastroenterology Research and Practice

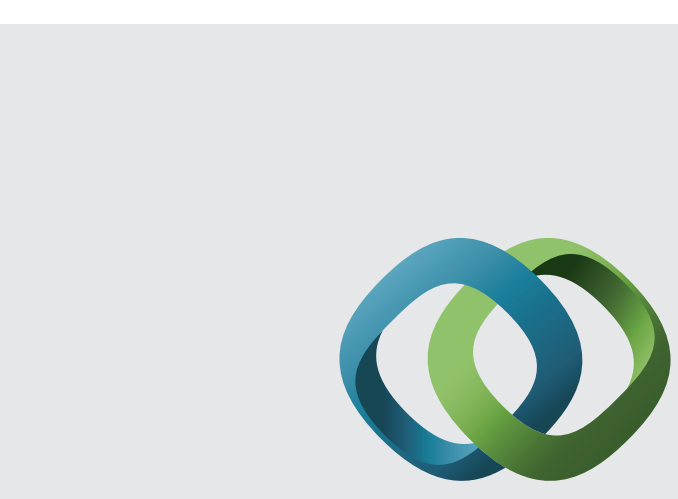

\section{Hindawi}

Submit your manuscripts at

http://www.hindawi.com
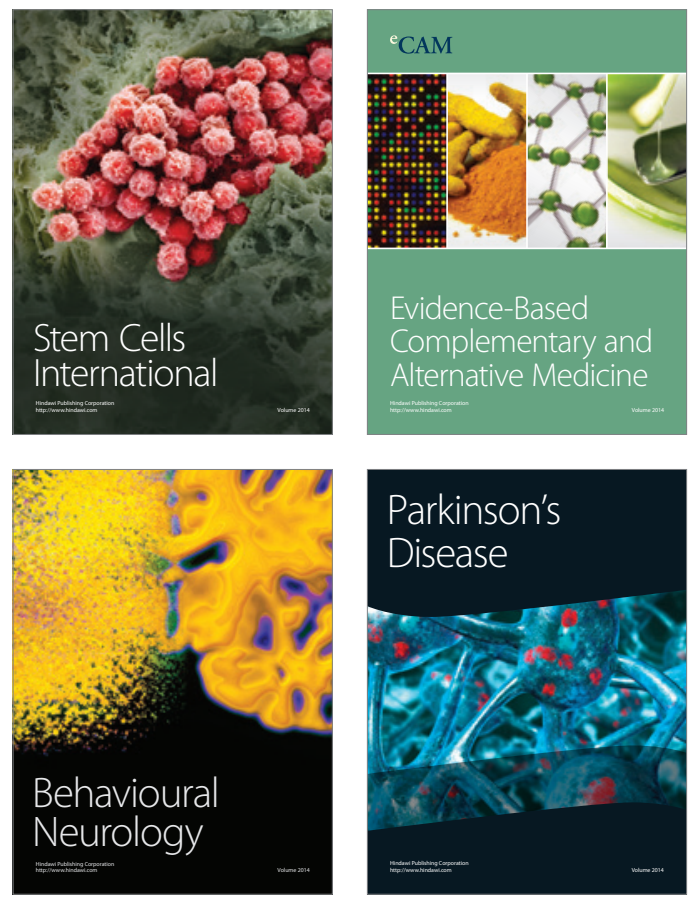
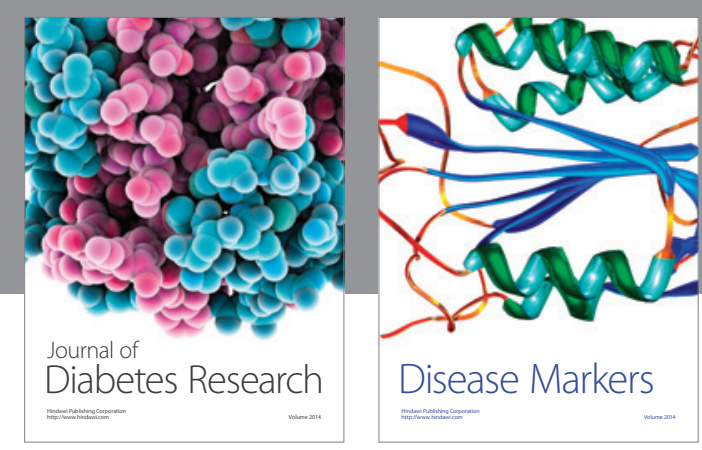

Disease Markers
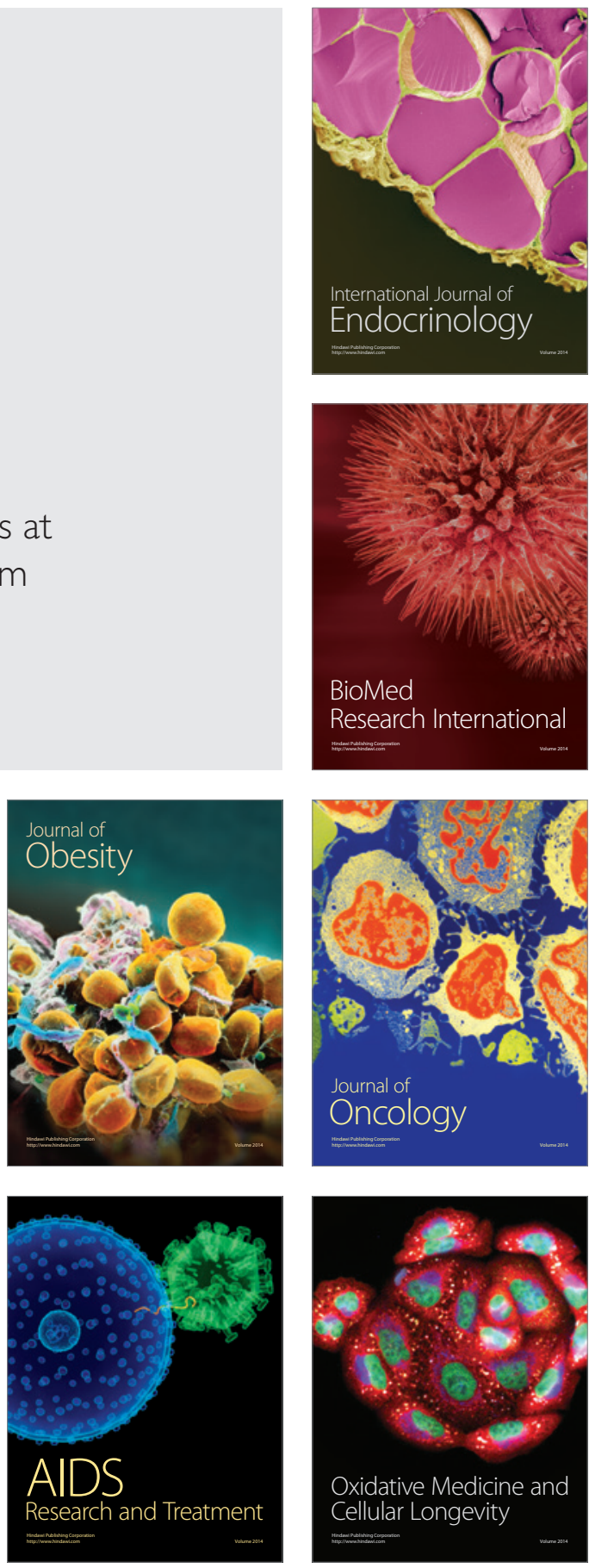